\title{
Free Vibration Analysis of Stiffened Laminated Composite Plates
}

\author{
Arafa El-Helloty \\ Associated Professor of structures, \\ Department of Civil Engineering, \\ Al-Azhar University,
}

\begin{abstract}
Stiffened Laminated composite plates are widely used in the aerospace, civil, marine, and automotive industries due to their high specific stiffness and strength, excellent fatigue resistance, long durability and many other superior properties compared to ordinary plates. In this paper, the effect of stiffener configuration, number of layers and boundary conditions on the free vibration response of stiffened laminated composite plates are examined with respect to natural frequencies and mode shapes. Six rectangular stiffeners configurations models are used with two types of boundary conditions which are simply and clamped supported. Comparative study is conducted to investigate the effect of stiffener configuration, number of layers and boundary conditions on the free vibration response of stiffened laminated composite plates using the finite element system ANSYS16.
\end{abstract}

\section{Keywords}

Laminated, composite plate, stiffener, cross-ply, number of layers, modal analysis, frequency.

\section{INTRODUCTION}

Stiffened laminated composite plates are extensively used in the construction of aerospace, civil, marine, automotive and other high performance structures due to their high strength to weight, stiffness to weight ratios and modulus, excellent fatigue resistance, long durability and many other superior properties compared to ordinary plates. The high specific strength and specific stiffness which are the bases of the superior structural performance of composite materials provide the composite materials many application choices. The correct and effective use of such laminates require more complex analysis in order to predict accurately the static and dynamic response of these structures under external loading. Most of the structures generally work under severe dynamic loading and different constrained conditions during their service life. To use stiffened laminated composite plates efficiently, an accurate knowledge of vibration characteristics is essential.

Problems are often occurred in structures due to vibrations and it is important to prevent such problems because it can cause structural fatigue and damage. Therefore, determination of the natural frequency of the stiffened laminated composite plates is a practical demand when the structures are subjected to periodic exciting loads. To assessing the natural frequency of the stiffened laminated composite plates, the modal analysis is required to obtain the data that are required to avoid resonance in structures affected by external periodic dynamic loads. Using the finite element method, many researchers have been devoted to the analysis of vibrations and dynamics, buckling and post buckling behavior, failure and damage analysis of laminated composite plates [1-12]. The finite element method is especially versatile and efficient for the analysis of complex structural behavior of laminated composite plates.
The vibration behavior of laminated composite plates without stiffener has been studied by extensive researchers[1$3,5,7,8,11,12]$. Also, a number of analytical and numerical models for the free vibration response of stiffened laminated composite plates have been presented in the literature. R. Rikards et al. (2001) [9] developed of triangular finite element for buckling and vibration analysis of laminated composite stiffened shells. For the laminated shell, an equivalent layer shell theory was employed and the first-order shear deformation theory including extension of the normal line was used. Numerical examples were presented and laminated composite plate with one stiffener was considered to show the accuracy and convergence characteristics of the element. G. Qing et al. (2006)[4] developed a novel mathematical model for free vibration analysis of stiffened laminated plates based on the semi-analytical solution of the state-vector equation theory. The transverse shear deformation and the rotary inertia were also considered in the model and the thickness of plate and the height of stiffeners were not restricted. several numerical examples that were plates with two stiffeners in one direction and a plate with four stiffeners in two orthogonal directions were analyzed and the convergence of all examples was tested. T. I. Thinh and N. N. Khoa (2008)[10] presented a new 9-noded rectangular stiffened plat element for the vibration analysis of stiffened laminated plates which was based on Mindlin's deformation plate theory. The stiffened plate element was a combination of basic rectangular element and beam bending component. Some problems on free vibration analysis of stiffened laminated composite plates that were made of graphite/ epoxy and glass/polyester with three stiffeners in one direction were analyzed with the presented element. L. Yanhong et al. (2014)[6] developed a three-dimensional semianalytical model for the free vibration analysis of stiffened composite laminates with interfacial imperfections that were based on the state space method and the linear spring layer model. Several numerical examples which were plates with two stiffeners in one direction were carried out to demonstrate an excellent predictive capability of this model in assessing the natural frequencies and vibration modes.

Therefore, the aim of this paper is to study the effect of stiffener configuration, number of layers and boundary conditions on the free vibration response of stiffened laminated composite plates using the finite element system ANSYS16. Simply and clamped supported stiffened laminated composite plates are considered with symmetric cross-ply laminates arrangements and the modal analysis is carried out.

\section{MODAL ANALYSIS}

The modal analysis is used to determine the vibration characteristics of a structure which it are natural frequencies and mode shapes while it is being designed. It also can be a starting point for another dynamic analysis such as a transient dynamic analysis, a harmonic response analysis, or a spectrum analysis. The dynamic behavior of the structure is defined by a 
special frequency spectrum which consisting of an infinite number of natural frequencies and mode shapes which can be found by knowing the geometrical shape, mass distribution, stiffness and boundary conditions of the structures. In general, the equation of motion for a linear dynamic system is [1-12]:

$[\mathrm{M}]\{\ddot{\mathrm{u}}\}+[\mathrm{C}]\{\dot{\mathrm{u}}\}+[\mathrm{K}]\{\mathrm{u}\}=\{\mathrm{F}(\mathrm{t})\}$

Where:

$[\mathrm{M}]=$ mass matrix, $[\mathrm{C}]=$ damping matrix, $[\mathrm{K}]=$ stiffness matrix, $\{\mathrm{F}(\mathrm{t})\}=$ time varying load vector, $\{\ddot{\mathrm{u}}\}=$ nodal acceleration vector, $\{\dot{\mathrm{u}}\}=$ nodal velocity vector and $\{\mathrm{u}\}=$ nodal displacement vector.

For free vibration the equation (1) becomes:

$[\mathrm{M}]\{\ddot{\mathrm{u}}\}+[\mathrm{C}]\{\dot{\mathrm{u}}\}+[\mathrm{K}]\{\mathrm{u}\}=0$

When undamped linear structures are initially displaced into a certain shape, they will oscillate indefinitely with the same mode shape but varying amplitudes. The oscillation shapes are called the mode shapes and the corresponding frequencies are called natural frequencies. For undamped linear structures, the equation (2) reduces to:

$[\mathrm{M}]\{\ddot{\mathrm{u}}\}+[\mathrm{K}]\{\mathrm{u}\}=0$

With no externally applied loads, the structure is assumed to vibrate freely in a harmonic form which is defined by:

$\mathrm{U}(\mathrm{t})=\varphi \sin (\mathrm{w} \mathrm{t}+\theta)$

which leads to the eigenvalue problem as:

$\left[[\mathrm{K}]-\mathrm{w}^{2}[\mathrm{M}]\right]\{\varphi\}=0$

Where $\mathrm{w}$ is the natural frequency and $\varphi$ is the corresponding mode shape of the structure.

\section{NUMERICAL EXAMPLE}

To study the effect of stiffener configuration, number of layers and boundary conditions on the free vibration response of stiffened laminated composite plates, the modal analysis of a laminated composite plate without and with stiffeners is considered with dimensions $1.0 \mathrm{~m} \times 1.0 \mathrm{~m}$ and thickness $h=1$ $\mathrm{mm}$ as shown in Fig. 1. Six rectangular stiffeners configurations models are used in the numerical studies with dimension $1.0 \mathrm{~m}$ x $0.10 \mathrm{~m}$ and thickness $h=1 \mathrm{~mm}$ as shown in Fig. 1 where model 1 has one stiffener in one direction, model 2 has two stiffeners in one direction, model 3 has three stiffeners in one direction, model 4 has four stiffeners in one direction, model 5 has two stiffeners in two orthogonal directions and model 6 has four stiffeners in two orthogonal directions.

In this study, two different boundary conditions which are simply supported and clamped supported on all four sides are considered. Laminates and stiffeners are composite plates consisting of four, six, eight and ten orthotropic plies of the same material and equal thickness with the overall thickness kept constant. Symmetric cross-ply laminates arrangements with simple and clamped boundary conditions are considered. A Epoxy/ Carbon composite material (UD 395 Gpa Prepreg) from ANSYS16 composite materials library is used and the materials properties are given as $E_{1}=209 \mathrm{GPa}, E_{2}=9.45 \mathrm{GPa}, E_{3}=9.45$ $\mathrm{GPa}, G_{12}=5.5 \mathrm{GPa}, G_{13}=5.0 \mathrm{GPa}, G_{23}=3.9 \mathrm{GPa}, v_{12}=0.27$, $v_{13}=0.27, v_{23}=0.4$ and $\rho=1540 \mathrm{~kg} / \mathrm{m}^{3}$ for Young's modulus, shear modulus, Poisson's ratio and density respectively.

\subsection{Method of analysis}

The modal analysis has been done by 8-node SHELL281 element in finite element system ANSYS16. The SHELL281 as shown in Fig. 2 is a eight-node element with six degrees of freedom at each node that are translations in the $\mathrm{x}, \mathrm{y}$, and $\mathrm{z}$ axes, and rotations about the $\mathrm{x}, \mathrm{y}$, and $\mathrm{z}$-axes. The element is suitable for analyzing thin to moderately- thick shell structures and it is appropriate for linear, large rotation and/ or large strain nonlinear applications. SHELL281 may be used for layered applications for modeling laminated composite shells or sandwich construction and the accuracy in modeling composite shells is governed by the first order shear deformation theory.
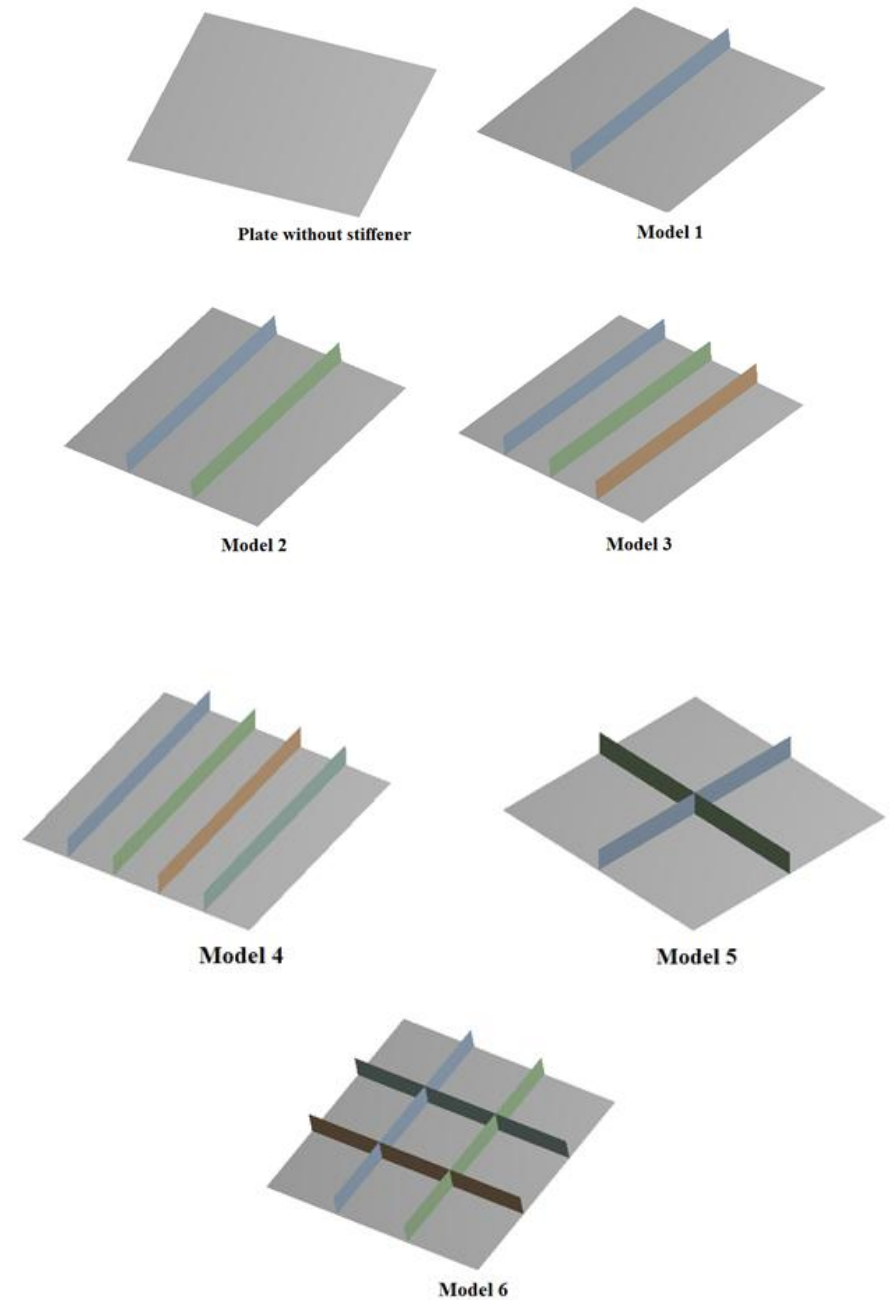

Fig. 1: Plates without and with stiffeners

$\boldsymbol{x}_{\boldsymbol{o}}=$ Element $\mathrm{x}$-axis if element orientation is not provided $\boldsymbol{x}=$ Element $\mathrm{x}$-axis if element orientation is provided. 


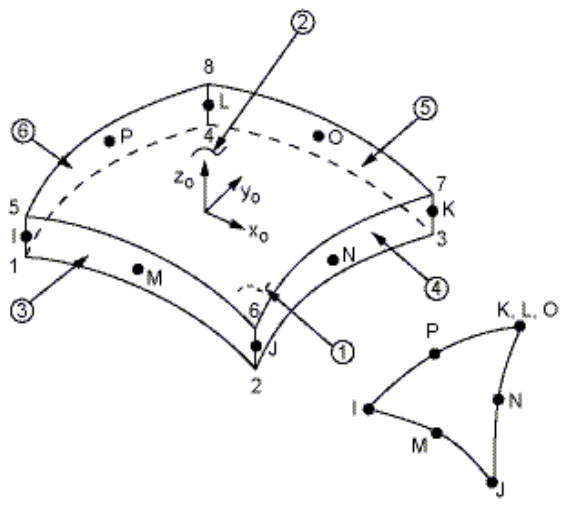

Fig. 2: 8-node SHELL281 element

\subsection{Numerical verification.}

To verify the analysis and results obtained in this study by the finite element system ANSYS16, A Free vibration analysis of ten layers simply supported laminated composite square plate is considered as reported in reference [8] by M. Reddy et al. The dimension of plate is $0.2 \mathrm{~m} \mathrm{x} 0.2 \mathrm{~m}$ and the orientation of layers of plate is symmetry which is $\left[0^{\circ} / 90^{\circ} / 0^{\circ} / 90^{\circ} / 0^{\circ}\right] \mathrm{s}$ and each layer has equal thickness with overall thickness of plate $0.00269 \mathrm{~m}$. The material is considered to be T300/934 CFRP with the mechanical properties as: $E_{1}=120 \mathrm{GPa}, E_{2}=7.9 \mathrm{GPa}, G_{12}=5.5$ $\mathrm{GPa}, v_{12}=0.33$ and $\rho=1580 \mathrm{~kg} / \mathrm{m}^{3}$ for Young's modulus, shear modulus, Poisson's ratio and density respectively.

The modal analysis is done for plate and the first natural frequency is carried out and compared with that obtained by $\mathrm{M}$. Reddy et al. As shown in Table 1, the result obtained by finite element system ANSYS16 is in very good agreement with the result that is obtained by M. Reddy et al.

Table 1: Verification of analysis and results

\begin{tabular}{|c|c|}
\hline Reference. & Natural frequency. HZ \\
\hline M. Reddy et al. & 302.05 \\
\hline ANSYS16 & 302.8 \\
\hline
\end{tabular}

Second example to verify the analysis and results obtained in this study by the finite element system ANSYS16 is a clamped laminated composite plate with one stiffener as reported in reference [9] by Rikards et al. The plate is consisting of eight a carbon/ epoxy composite material (AS1/3501-6) layers and the dimension of plate is $250 \mathrm{~mm} \times 500 \mathrm{~mm}$. The orientation of layers of plate is symmetry which is $0 /+45 /-45 / 90 / 90 /-45 /+45 / 0$ and each layer has equal thickness $=0.13 \mathrm{~mm}$ with overall thickness of plate $1.04 \mathrm{~mm}$. The stiffener is consists of symmetry cross-ply laminate with 28 layers and the orientation of layers is $\left[0_{7}, 90_{7}\right]_{\mathrm{s}}$ and each layer has equal thickness $=0.13$ $\mathrm{mm}$ with overall thickness of stiffener $3.64 \mathrm{~mm}$ and the width of stiffener is $10.5 \mathrm{~mm}$. The material laminates of plate and stiffener is a carbon/ epoxy composite material (AS1/3501-6) and the resulting composite material and the material properties are $E_{1}=128 \mathrm{GPa}, E_{2}=11 \mathrm{GPa}, G_{12}=G_{13}=4.48 \mathrm{GPa}, G_{23}=$ $1.53 \mathrm{GPa}, v_{12}=0.25$, and $\rho=1500 \mathrm{~kg} / \mathrm{m}^{3}$ for Young's modulus, shear modulus Poisson's ratio and density respectively. The modal analysis is done for plate and the five natural frequencies are carried out and compared with results that obtained by Rikards et al. As shown in Table 2, the result obtained by finite element system ANSYS16 is in good agreement with results that are obtained by Rikards et al.
Table 2: Verification of analysis and results

\begin{tabular}{|c|c|c|c|c|c|}
\hline \multirow{2}{*}{ Reference. } & \multicolumn{5}{|c|}{ Natural frequency. HZ } \\
\cline { 2 - 6 } & $\begin{array}{c}\text { Mode } \\
\mathbf{1}\end{array}$ & $\begin{array}{c}\text { Mode } \\
\mathbf{2}\end{array}$ & $\begin{array}{c}\text { Mode } \\
\mathbf{3}\end{array}$ & $\begin{array}{c}\text { Mode } \\
\mathbf{4}\end{array}$ & $\begin{array}{c}\text { Mode } \\
\mathbf{5}\end{array}$ \\
\hline $\begin{array}{c}\text { Rikards et } \\
\text { al. }\end{array}$ & 215 & 235.5 & 274.5 & 315.4 & 361.4 \\
\hline ANSYS16 & 215.49 & 249.19 & 299.02 & 307.31 & 371.15 \\
\hline
\end{tabular}

\subsection{Results and discussion}

The modal analysis has been carried out and the ten natural frequencies values and mode shapes for plates without and with stiffener are obtained.

To study the effect of stiffener configuration, number of layers and boundary conditions on the free vibration response of stiffened laminated composite plates, the results obtained are analyzed. For simplicity, the results are presented by charts as follows:

\subsubsection{Effect of stiffener configuration}

Fig. 3 presents the mode shape 1 for simply supported plates without and with stiffener for number of layers four. Fig. 4 presents the mode shape 5 for simply supported plates without and with stiffener for number of layers six. Fig. 5 presents the mode shape 7 for clamped supported plates without and with stiffener for number of layers eight. Fig. 6 presents the mode shape 10 for clamped supported plates without and with stiffener for number of layers ten.

Fig. 7 to Fig. 10 present the effect of stiffener configuration on the performance of the frequency for four, six, eight and ten layers simply supported plate respectively. Fig. 11 to Fig. 14 present the comparison of stiffener configuration on the frequency for four, six , eight and ten layers simply supported plate respectively.

Fig. 15 to Fig. 18 present the effect of stiffener configuration on the performance of the frequency for four, six, eight and ten layers clamped supported plate respectively. Fig. 19 to Fig. 22 present the comparison of stiffener configuration on the frequency for four, six , eight and ten layers clamped supported plate respectively.

From the previous figures, it is noticed that:

In generally, for different boundary conditions of plate, there is an increase in the natural frequency for plates with stiffeners when it is compared with the plate without stiffener for all number of layers. As the number of stiffeners increases the natural frequency increases with the increase of the number of modes for all number of layers. The natural frequency has the biggest values with model 4 where the four stiffeners are configuration in one direction and it has the lowest values with model 1 where one stiffener is configuration in one direction for all number of layers.

For the stiffeners with simply supported plates, the critical ones with respect to high values of natural frequency are the model 4 , the model 3 and the model 6 respectively for first five modes with the increase of the number of layers. Also, the critical ones with respect to low values of natural frequency are the model 1 , the model 5 and the model 2 respectively for first four modes with the increase of the number of layers. For the stiffeners with clamped supported plates, the critical ones with respect to high values of natural frequency are the model 4 , the model 6 and the model 3 respectively for first five modes with the increase of the number of layers. Also, the critical ones with respect to low values of natural frequency are the model 1 , the model 5 and the 
model 2 respectively for first four modes with the increase of the number of layers.

\section{A. Modal
Total Deformution
Type Total Deformation
frequency: $3.24(4 \mathrm{~Hz}$ \\ Fequency: $1.2464 \mathrm{~Hz}$}

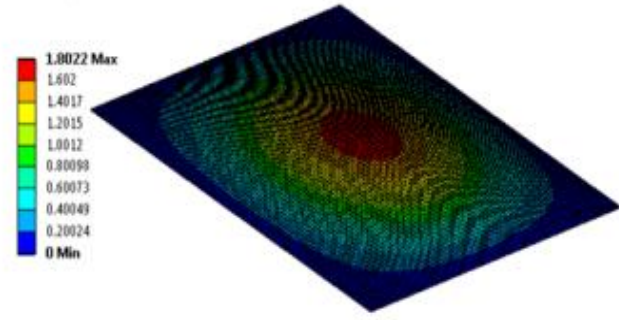

A: Model

Total Deformstion
Type: Total Oeformation
Frequency 39.046 Ht

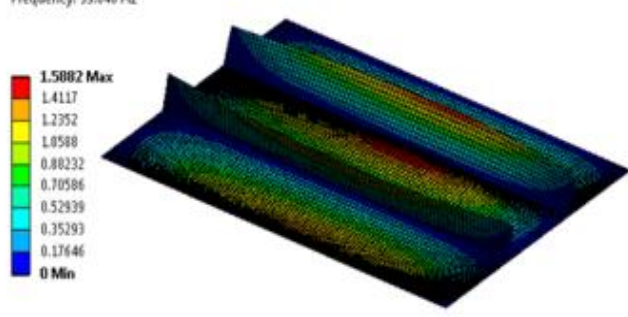

Total Deformation

Type: Total Deformation

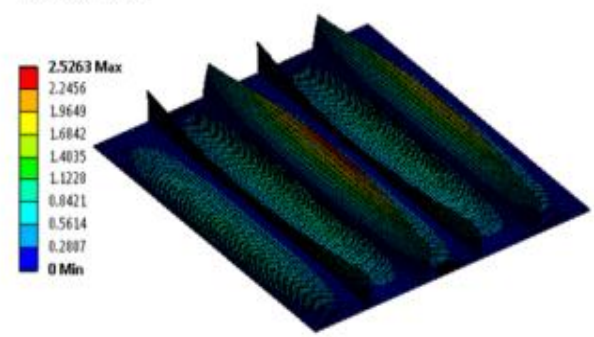

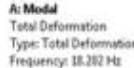

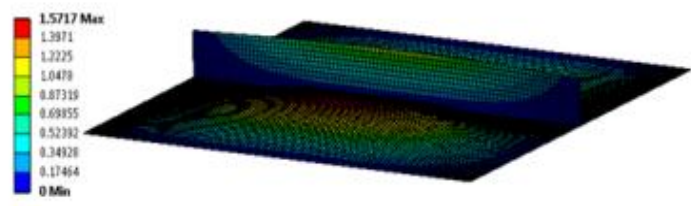

A. Model

Total Deformation
Type Total Deformation

Frequency: $59.222 \mathrm{~Hz}$

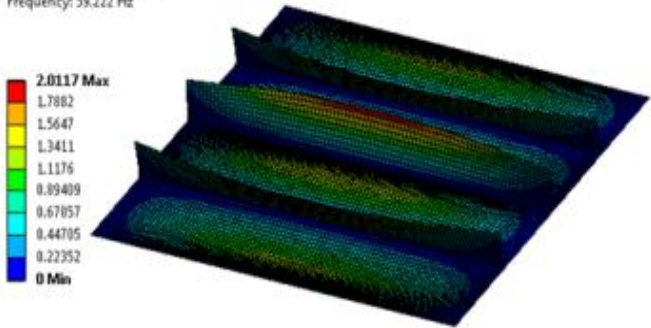

A: Modal

Total Deformation

Type: Total Deformation

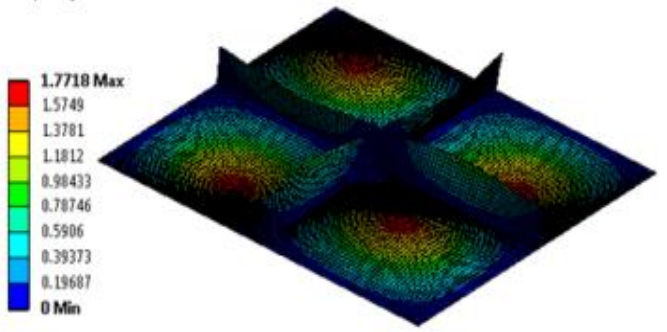

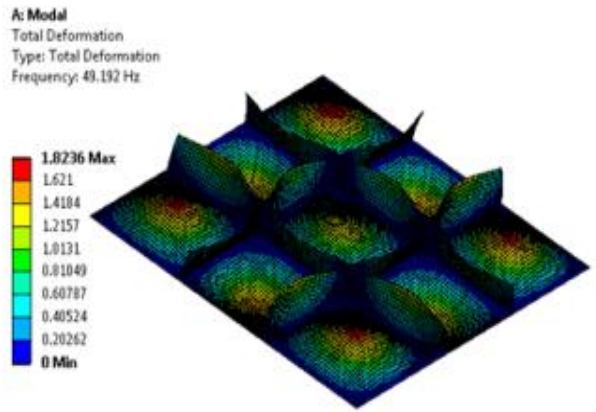

Fig. 3: Mode shape 1 for simply supported plates without and with stiffener for number of layers four 
A: Modal

Total Deformation 5

Type: Total Deformation

Frequency: $34.597 \mathrm{~Hz}$

Unit $m$

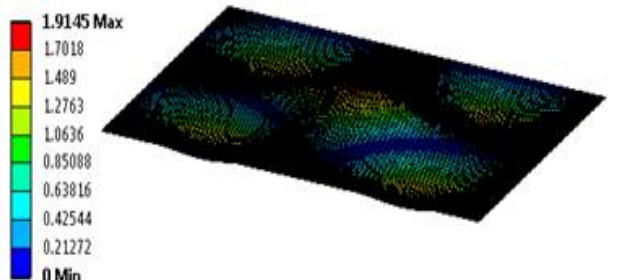

A:Modal

Total Deformation 5

Type: Total Deformation

frequency: $52.098 \mathrm{~Hz}$

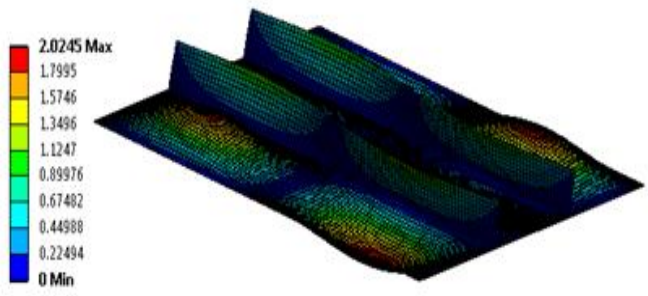

\section{A: Modal}

Total Deformation 5

Type: Total Deformation

Frequency: $83.448 \mathrm{~Hz}$

Unit: $m$

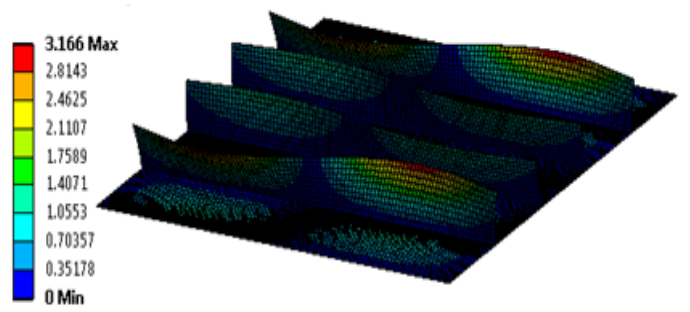

A: Modal

Total Deformation 5

Type: Total Deformation

Frequency: $36.841 \mathrm{~Hz}$

Unit: $m$

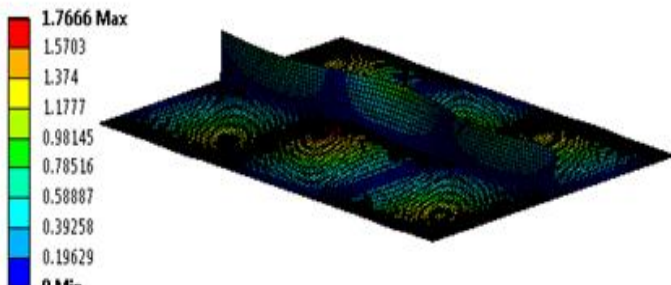

A: Modal

Total Deformation 5

Type: Total Deformation

Frequency, $13.503 \mathrm{~Hz}$

Unit $m$

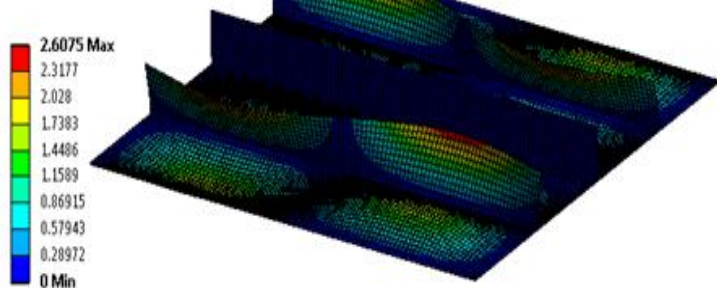

A:Modal

Total Deformation 5

Type: Total Deformation

Frequency: $65.648 \mathrm{~Hz}$

Unit: $m$

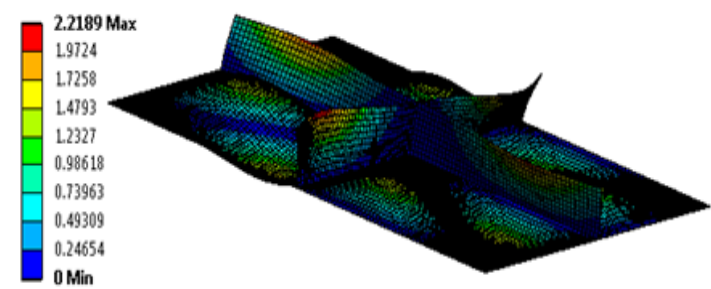

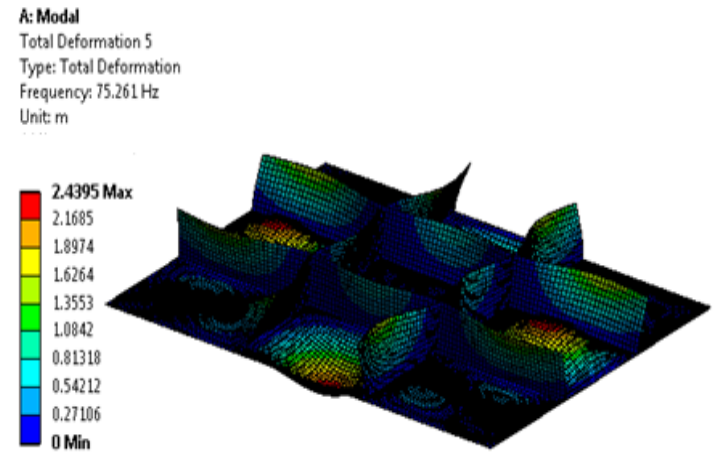

Fig. 4: Mode shape 5 for simply supported plates without and with stiffener for number of layers six 
A: Modal

Total Deformation 7

Type: Total Deformation

Fiequenc/ 54

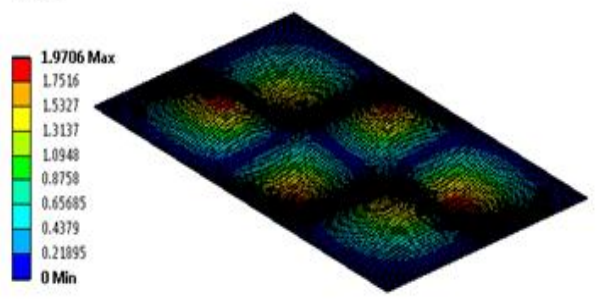

A: Modal

Total Deformation

Type: Total Deformatio

Frequency: $85.738 \mathrm{~Hz}$

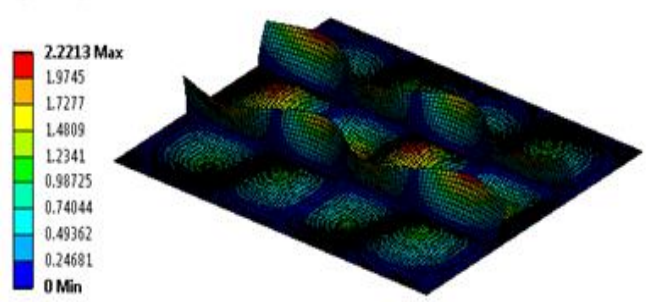

0 Min

A: Modal

Total Deformation 7

Type: Total Deformation

Frequency: 105. $\mathrm{Hz}$

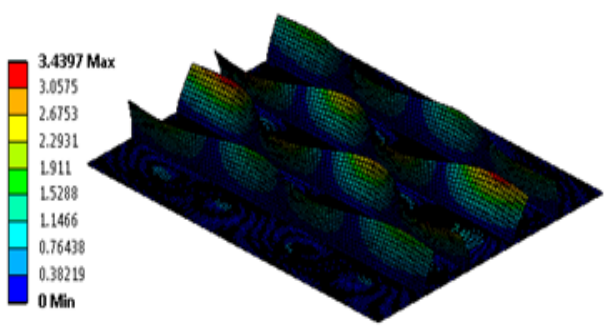

A: Modal
Total Deformation 1

Type: Total Deformstion

Frequency: $78.861 \mathrm{~Hz}$

Unit $m$

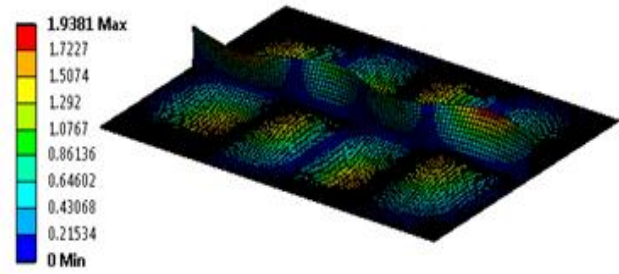

A: Modal

Total Deformation $?$

Type: Total Deformation

Type: Tots 0 erormation

Frequen

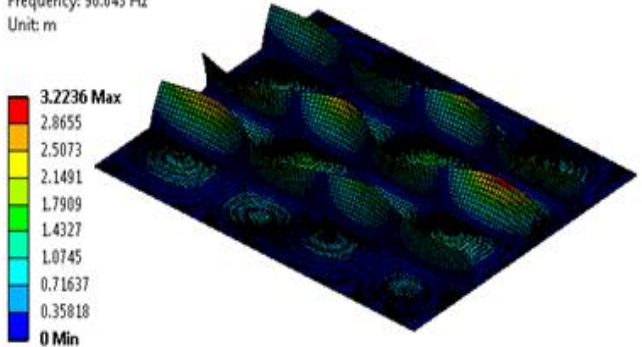

A.Model

Total Deformation ?

Type: Total Deformatio

Frequency: $86.016 \mathrm{~Hz}$

Unit $m$

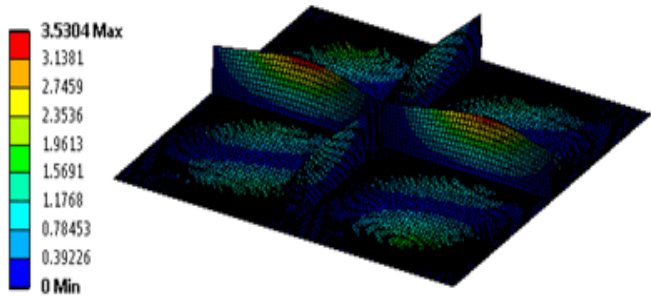

A: Modal

Total Deformation ?

Type: Total Deformation

Frequency: $102.88 \mathrm{~Hz}$

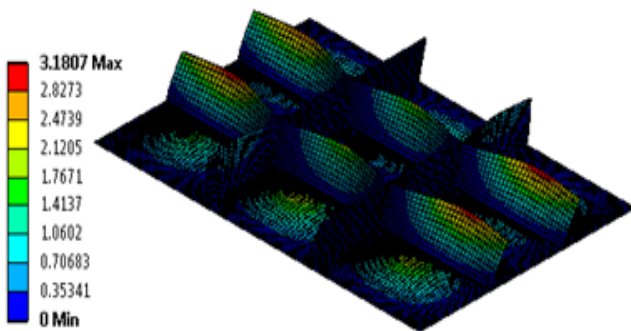

Fig. 5: Mode shape 7 for clamped supported plates without and with stiffener for number of layers eight 

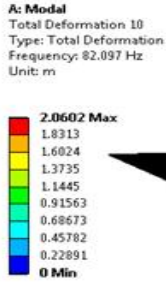

\section{A: Mode} Total Deformation 10
Type: Total Deformation
Frequency: $88.886 \mathrm{~Hz}$
Unite $\mathrm{m}$

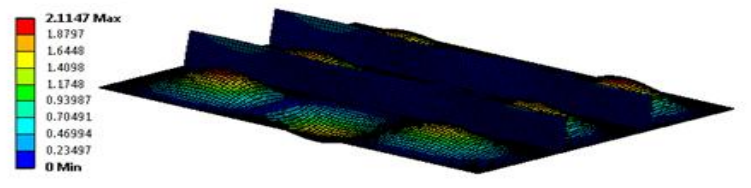

A: Modal Type: Total Defor of 10
Treation

\section{$18906 \max$}

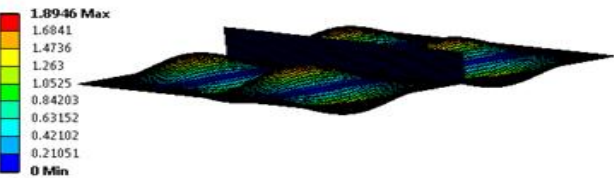

A: Modal

Total Deformation 10

Frequency: $108.44 \mathrm{~Hz}$

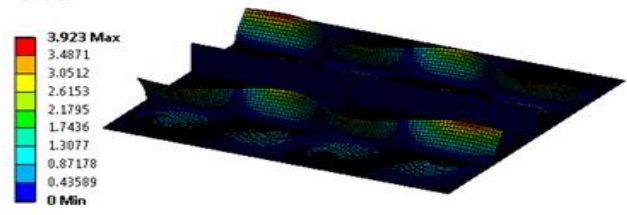

A: Modal

Total Deformation 10

Type: Total Deformation

Frequency: $113.11 \mathrm{~Hz}$

Unit $m$

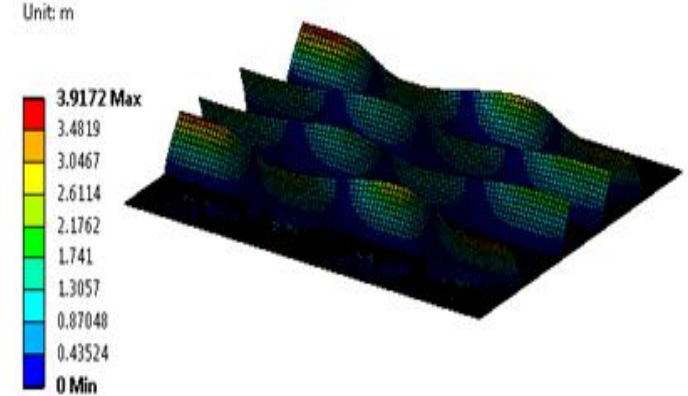

A: Modal

Total Deformation 10

Type: Total Deformation

Frequency: $103.49 \mathrm{~Hz}$

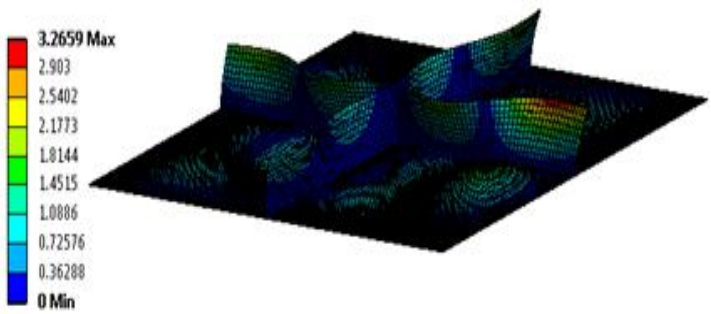

A: Modal

Total Deformation 10

Type: Total Deformation

frequency: $166.32 \mathrm{~Hz}$

Unit $m$

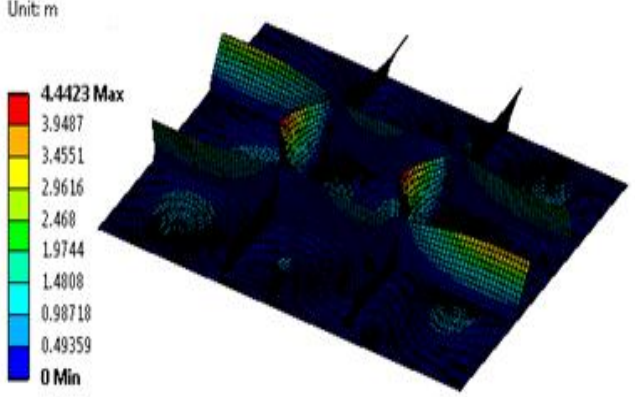

Fig. 6: Mode shape 10 for clamped supported plates without and with stiffener for number of layers ten 


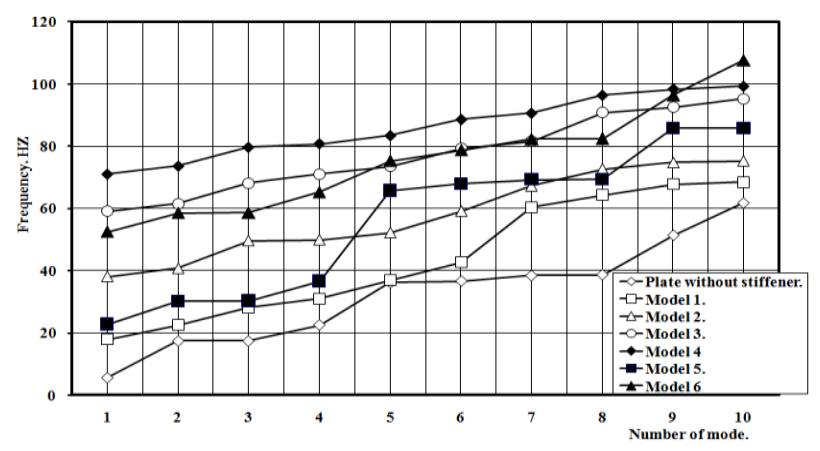

Fig. 7: Effect of stiffener configuration on the performance of the frequency for four layers simply supported plate

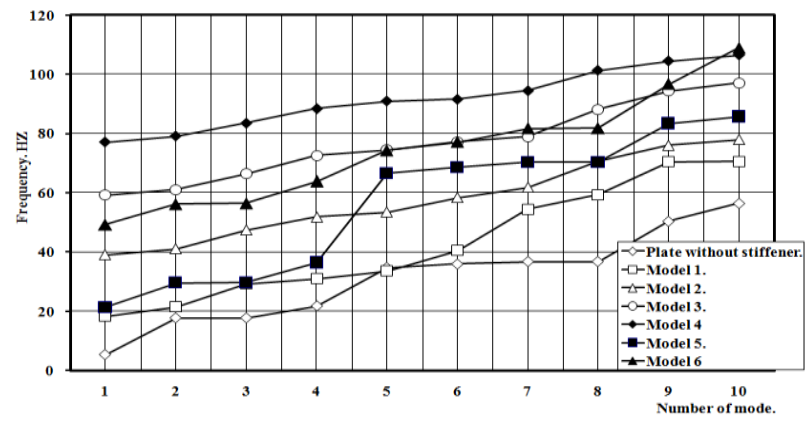

Fig. 8: Effect of stiffener configuration on the performance of the frequency for six layers simply supported plate

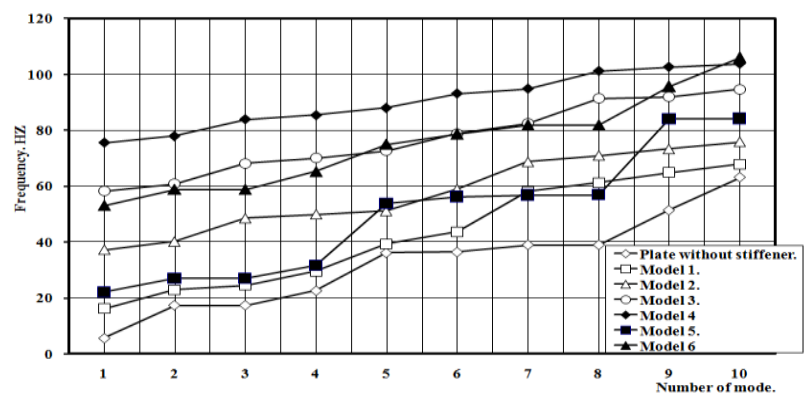

Fig. 9: Effect of stiffener configuration on the performance of the frequency for eight layers simply supported plate

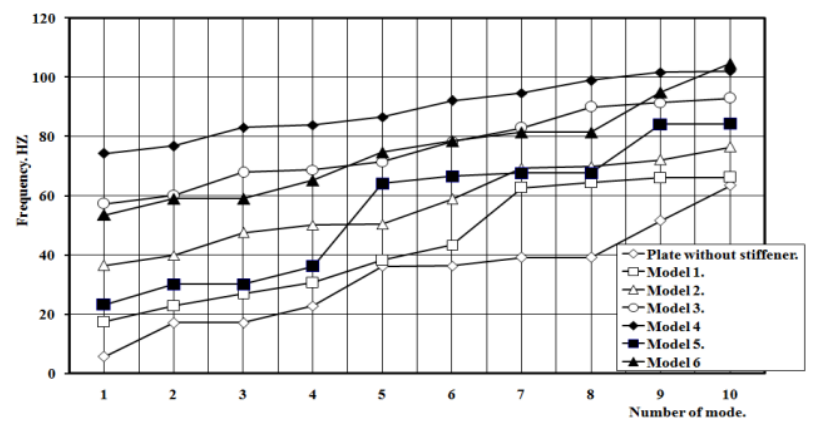

Fig. 10: Effect of stiffener configuration on the performance of the frequency for ten layers simply supported plate

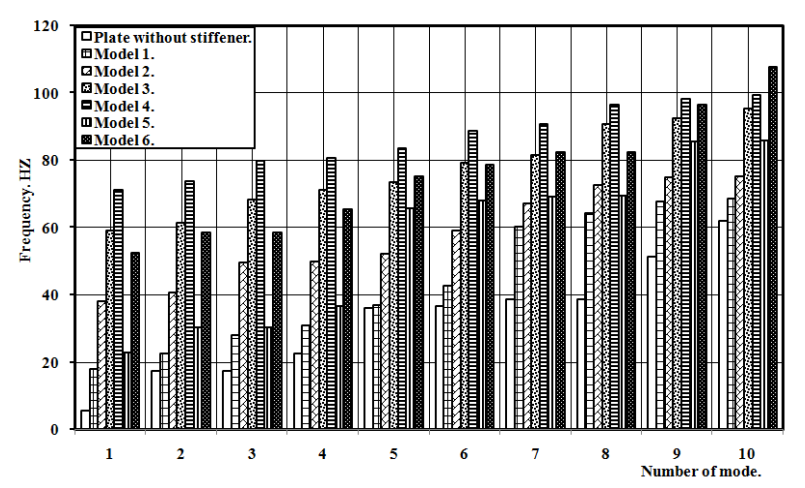

Fig. 11: Comparison of stiffener configuration on the frequency of four layers simply supported plate

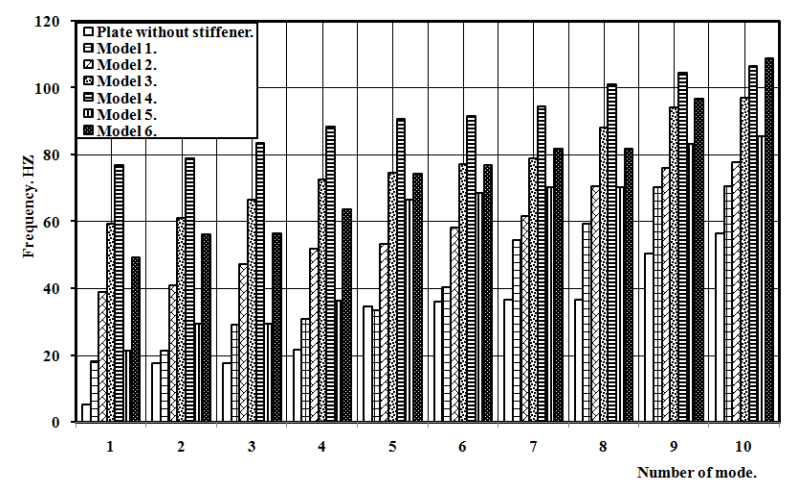

Fig. 12: Comparison of stiffener configuration on the frequency of six layers simply supported plate

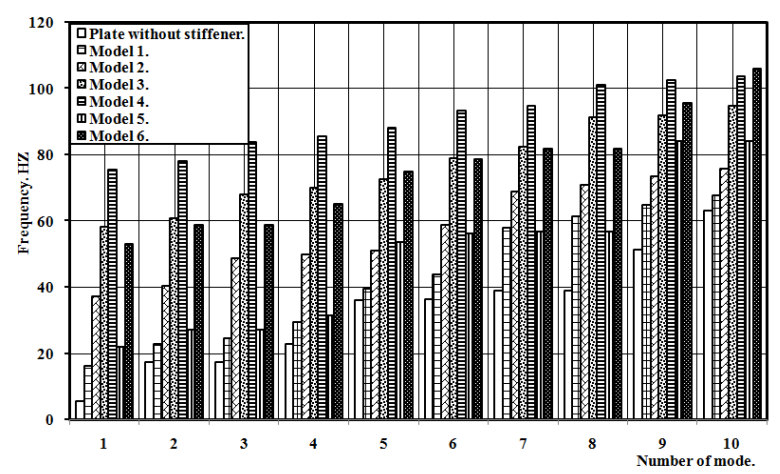

Fig. 13: Comparison of stiffener configuration on the frequency of eight layers simply supported plate

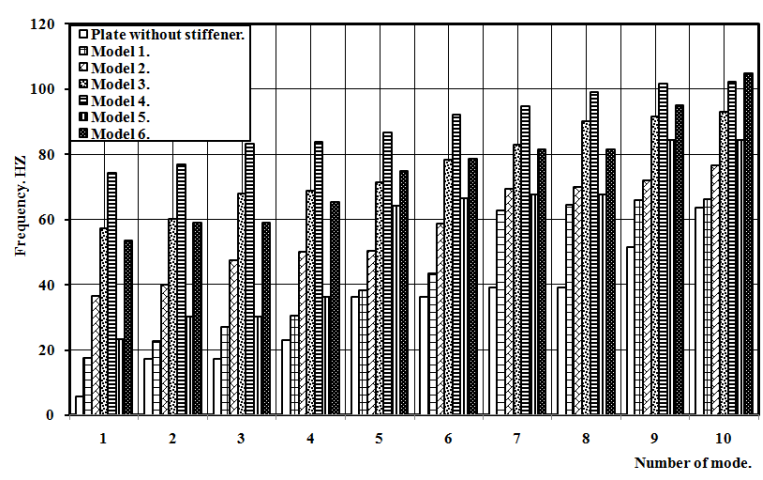

Fig. 14: Comparison of stiffener configuration on the frequency of ten layers simply supported plate 


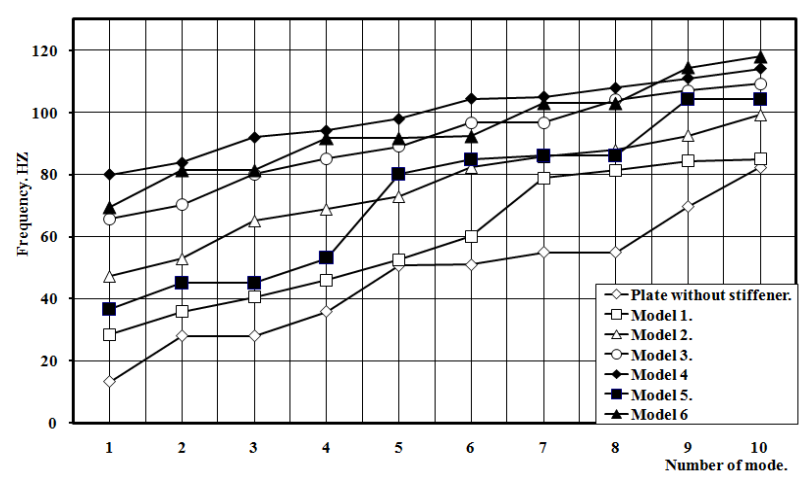

Fig. 15: Effect of stiffener configuration on the performance of the frequency for four layers clamped supported plate

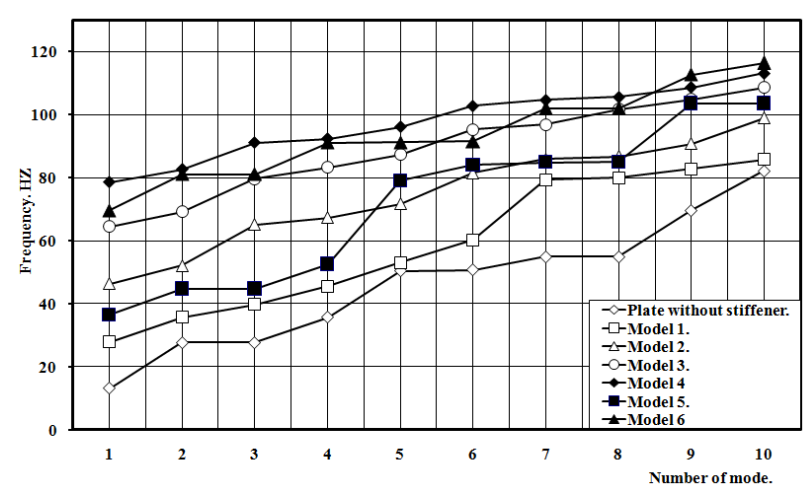

Fig. 16: Effect of stiffener configuration on the performance of the frequency for six layers clamped supported plate

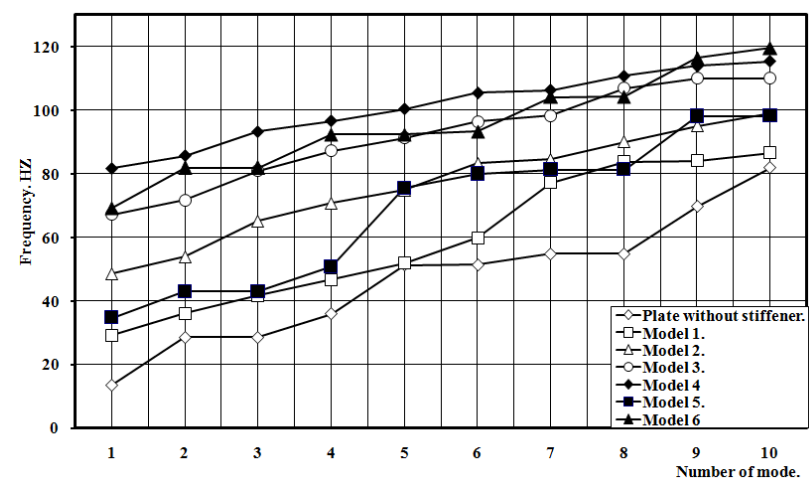

Fig. 17: Effect of stiffener configuration on the performance of the frequency for eight layers clamped supported plate

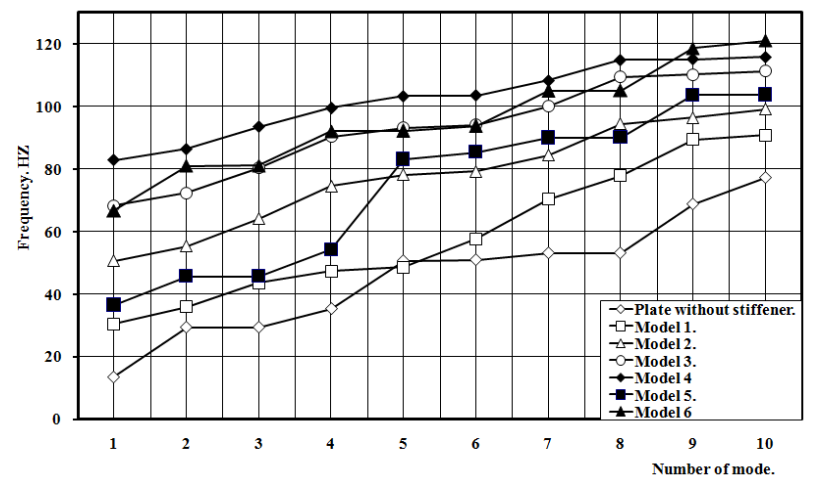

Fig. 18: Effect of stiffener configuration on the performance of the frequency for ten layers clamped supported plate

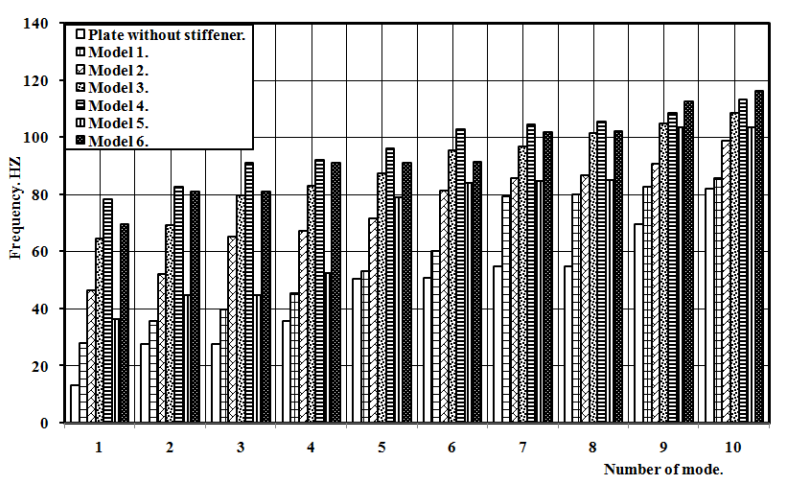

Fig. 19: Comparison of stiffener configuration on the frequency of four layers clamped supported plate

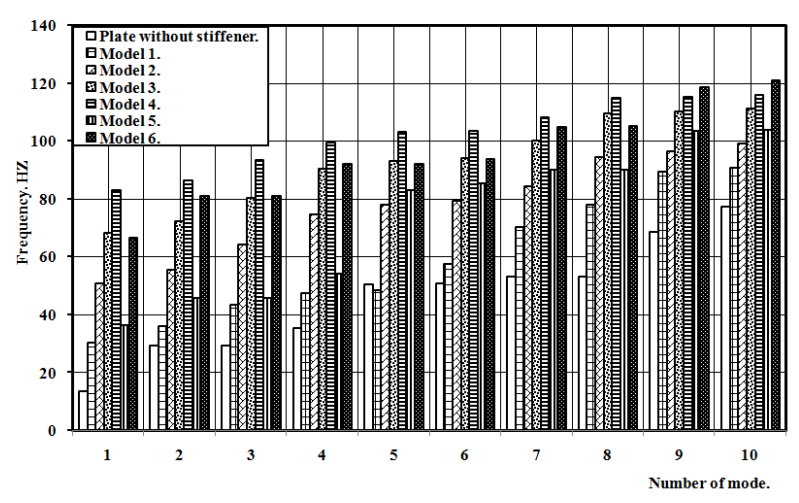

Fig. 20: Comparison of stiffener configuration on the frequency of six layers clamped supported plate

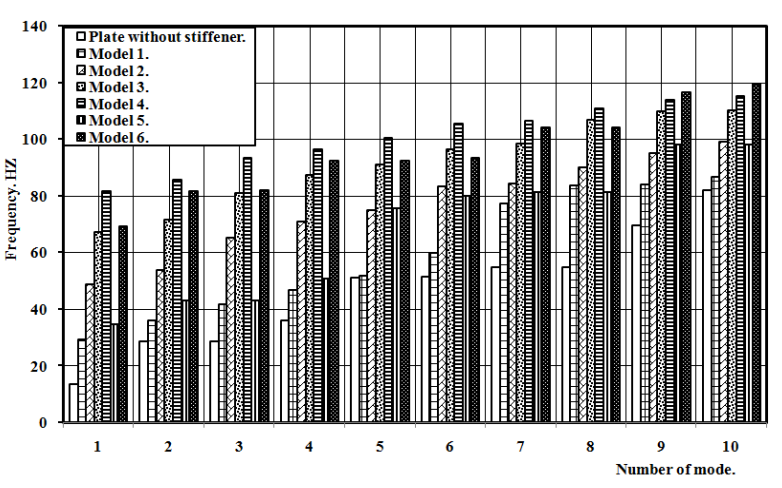

Fig. 21: Comparison of stiffener configuration on the frequency of eight layers clamped supported plate

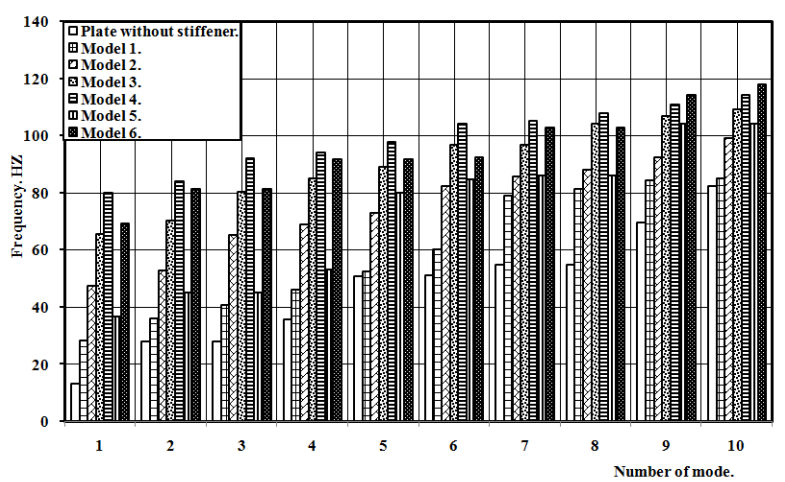

Fig. 22: Comparison of stiffener configuration on the frequency of ten layers clamped supported plate 


\subsubsection{Effect of number of layers.}

Fig. 23 to Fig. 25 present effect of number of layers on the performance of frequency for simply supported plate for modes 1, 2, 3, 4, 9 and 10 respectively. Fig. 26 to Fig. 28 present comparison of number of layers on the performance of frequency for simply supported plate for modes 1,2, 3, 4, 9 and 10 respectively.

Fig. 29 to Fig. 31 present effect of number of layers on the performance of frequency for clamped supported plate for modes 1, 2, 3, 4, 9 and 10 respectively. Fig. 32 to Fig. 34 present comparison of number of layers on the performance of frequency for clamped supported plate for modes 1, 2, 3, 4, 9 and 10 respectively.

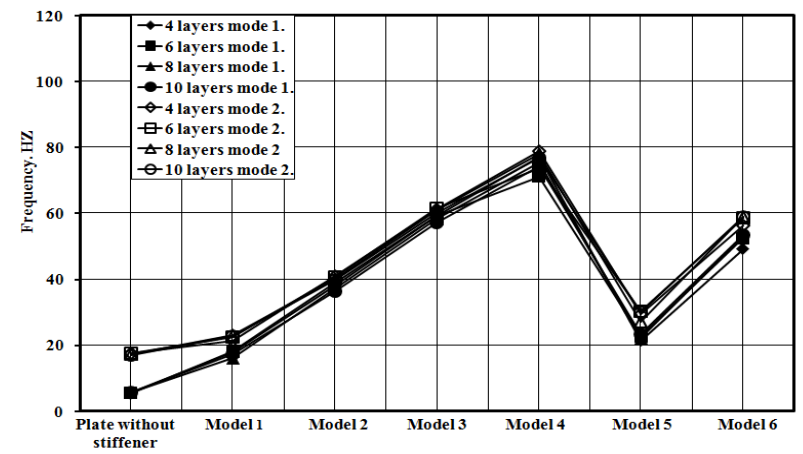

Fig. 23: Effect of number of layers on the performance of frequency for simply supported plate for modes 1 and 2

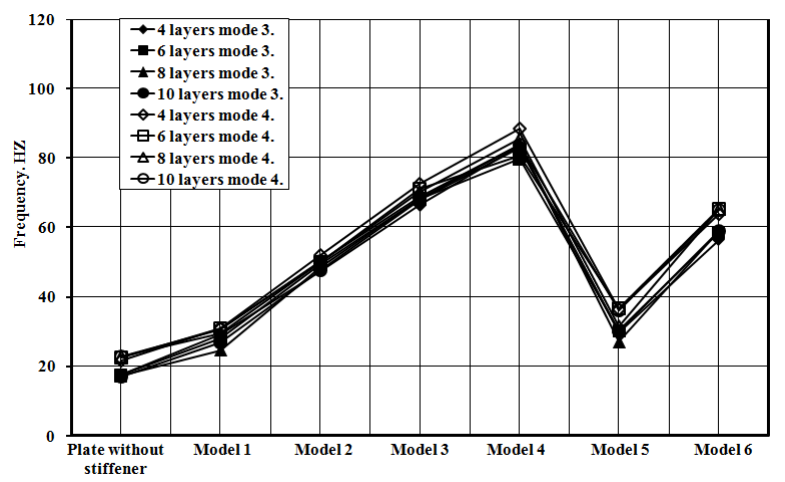

Fig. 24: Effect of number of layers on the performance of frequency for simply supported plate for modes 3 and 4

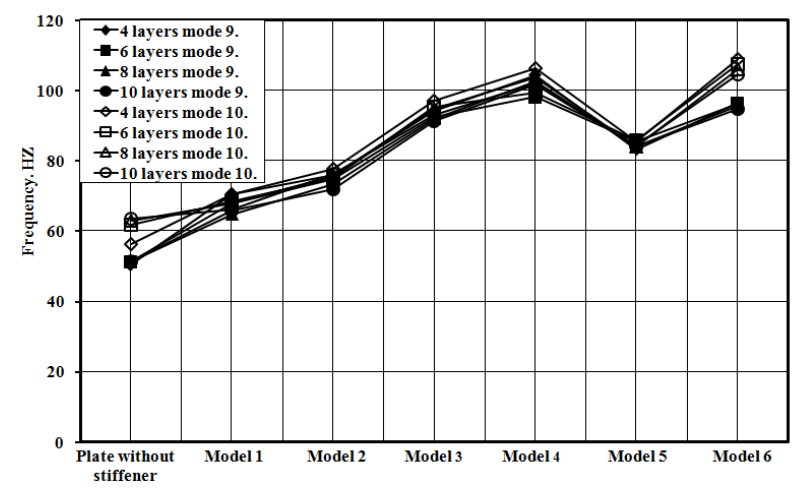

Fig. 25: Effect of number of layers on the performance of frequency for simply supported plate for modes 9 and 10

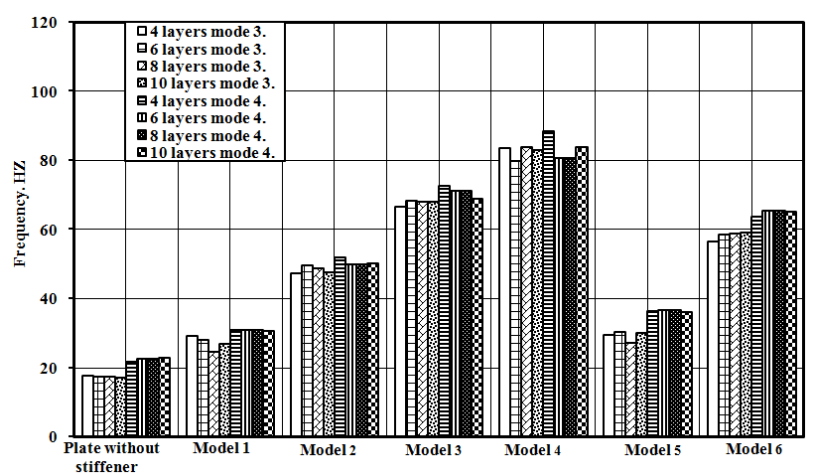

Fig. 26: Comparison of number of layers on the frequency of simply supported plate for modes 1 and 2

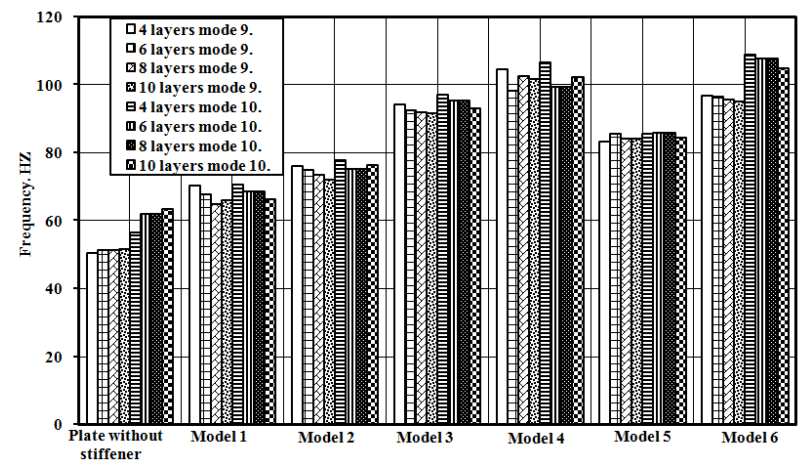

Fig. 27: Comparison of number of layers on the frequency of simply supported plate for modes 3 and 4

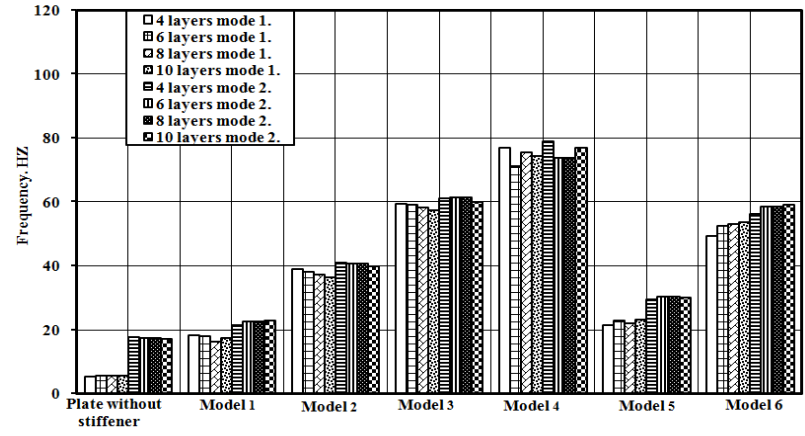

Fig. 28: Comparison of number of layers on the frequency of simply supported plate for modes 9 and 10

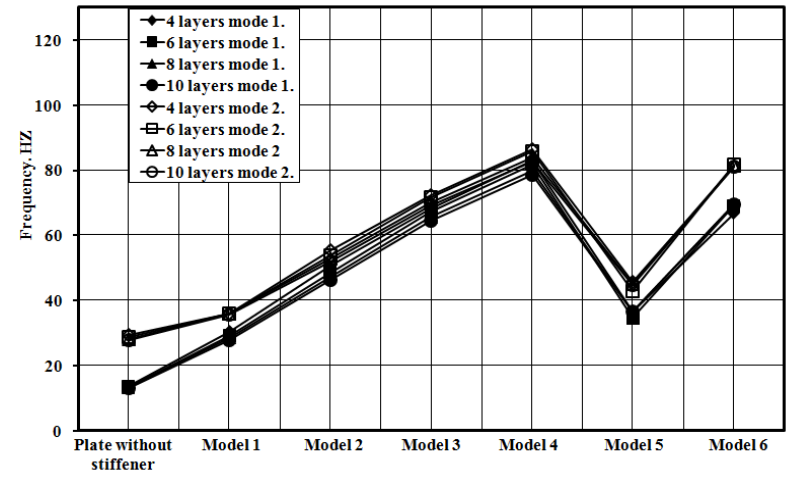

Fig. 29: Effect of number of layers on the performance of frequency for clamped supported plate for modes 1 and 2 


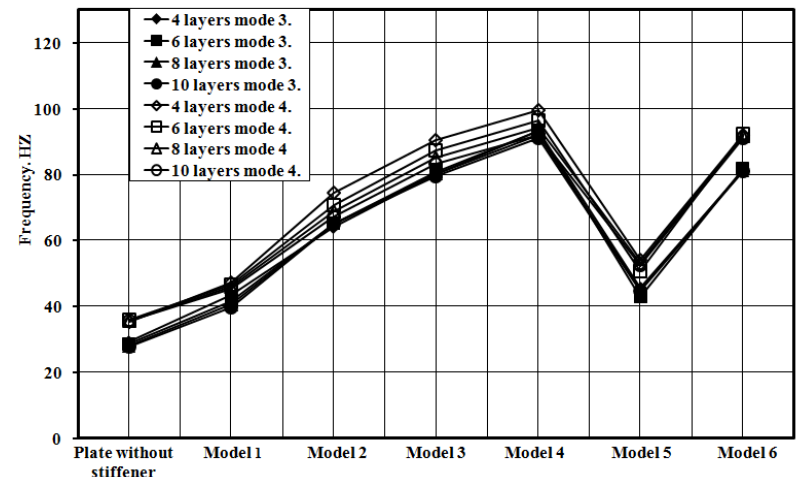

Fig. 30: Effect of number of layers on the performance of frequency for clamped supported plate for modes 3 and 4

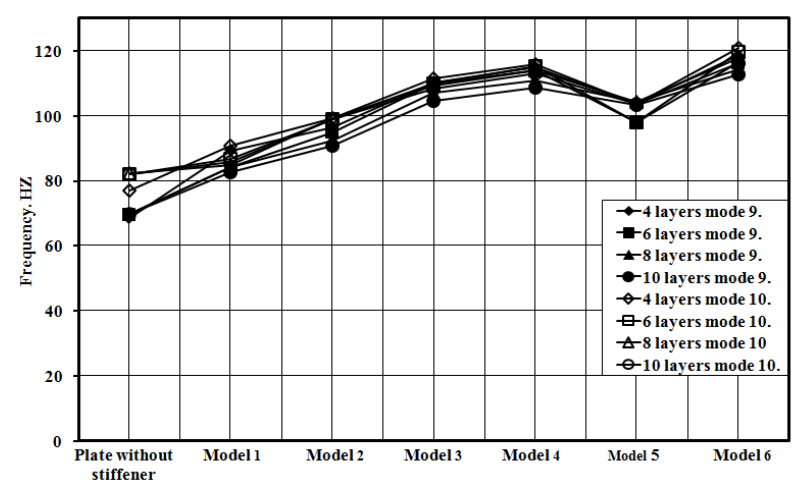

Fig. 31: Effect of number of layers on the performance of frequency for clamped supported plate for modes 9 and 10

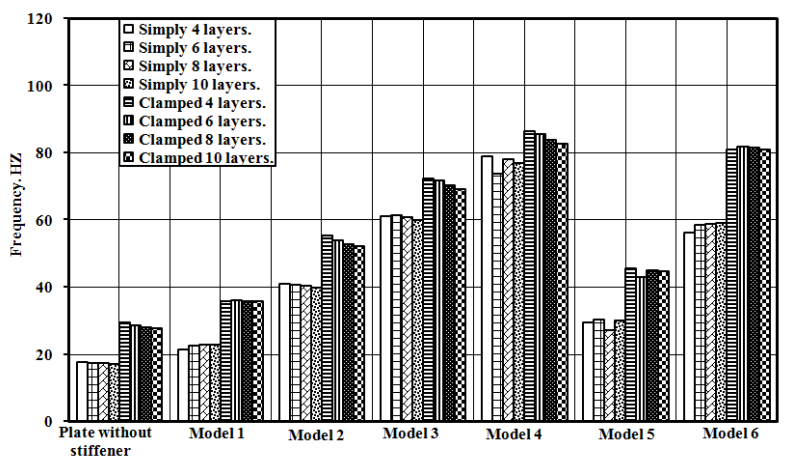

Fig. 32: Comparison of number of layers on the frequency of clamped supported plate for modes 1 and 2

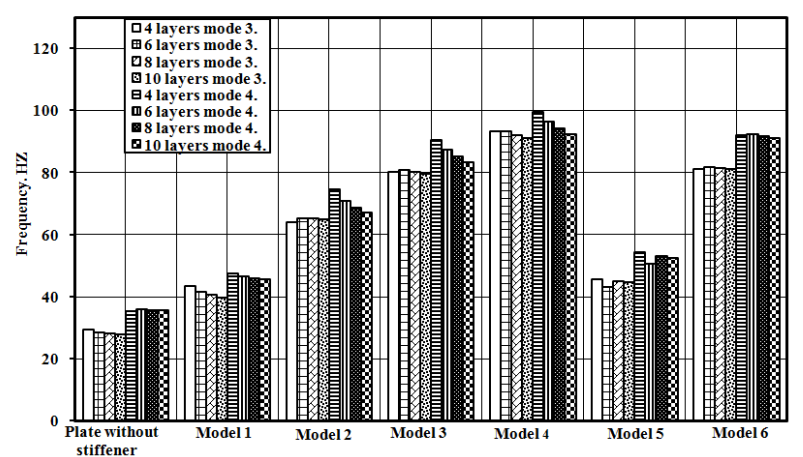

Fig. 33: Comparison of number of layers on the frequency of clamped supported plate for modes 3 and 4

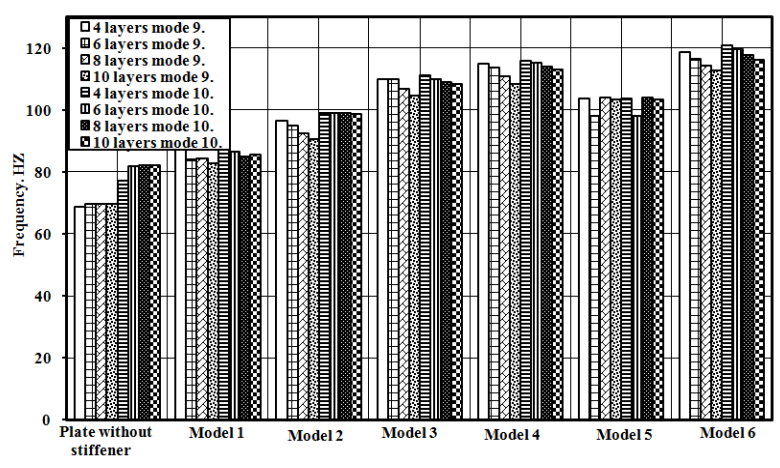

Fig. 34: Comparison of number of layers on the frequency of clamped supported plate for modes 9 and 10

From the previous figures, it is noticed that:

In generally, for different boundary conditions of plate, as the number of layers increases there is an increase in the natural frequency for plates with stiffeners when it is compared with the plate without stiffener with the increase of the number of modes. For different boundary conditions of plate, as the number of layers increases there is no much variation in the natural frequency for all models with the increase of the number of modes. The natural frequency has the biggest values when the number of layers equals four for all models with the increase of the number of modes.

\subsubsection{Effect of boundary conditions.}

Fig. 35 to Fig. 38 present the comparison of stiffener configuration on the frequency for simply and clamped supported plate for modes 1, 2, 3 and 10 respectively.

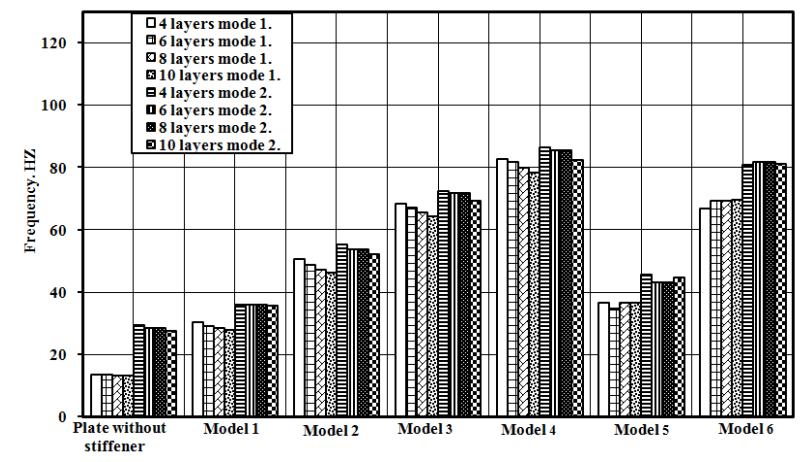

Fig. 35: Comparison of stiffener configuration on the frequency of simply and clamped supported plate for mode1

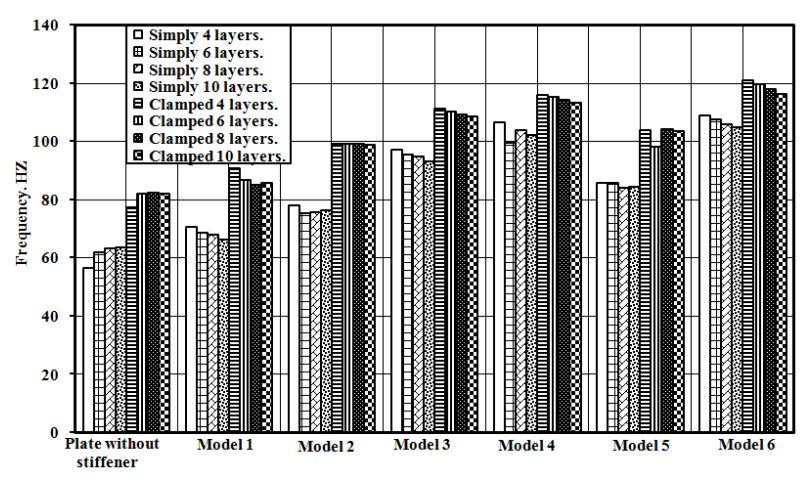

Fig. 36: Comparison of stiffener configuration on the frequency of simply and clamped supported plate for mode 


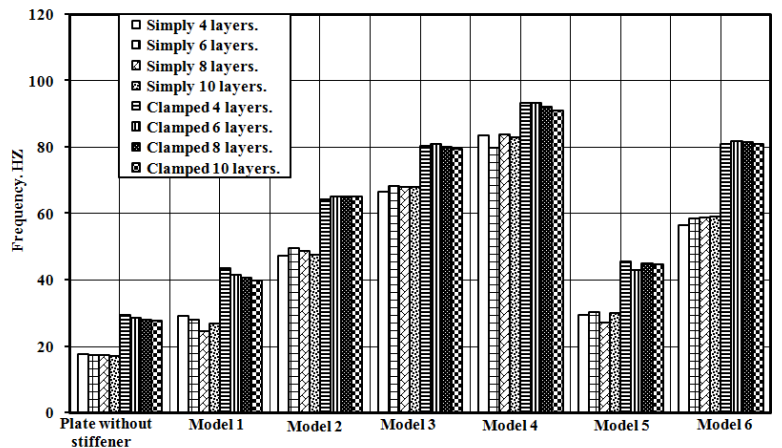

Fig. 37: Comparison of stiffener configuration on the frequency of simply and clamped supported plate for mode 3

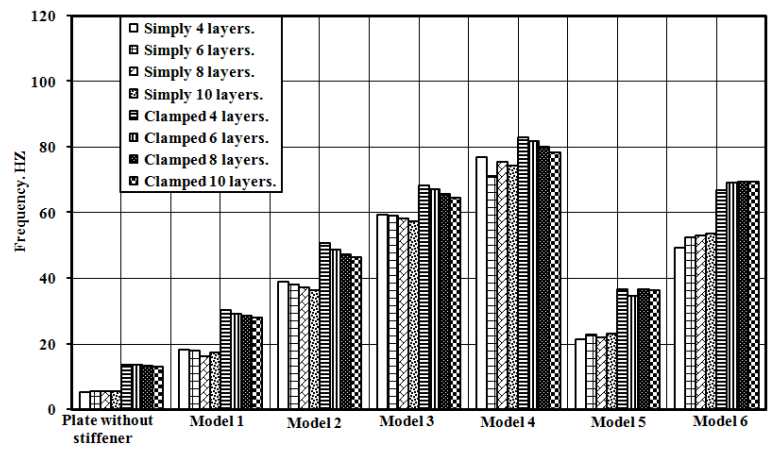

Fig. 38: Comparison of stiffener configuration on the frequency of simply and clamped supported plate for mode 10

From the previous figures, it is noticed that:

In general, for simply and clamped supported stiffened plates, there is an increase in the natural frequency for plates with stiffeners when it is compared with the plate without stiffener with the increase of the number of modes for all models and all number of layers. The natural frequency for stiffened plates with clamped supported is higher than that for stiffened plates with simply supported with the increase of the number of modes for all models and all number of layers. The natural frequency has the biggest values with clamped supported stiffened plates when the number of layers equals four for all models with the increase of the number of modes.

\section{CONCLUSIONS}

In this paper, the modal analysis of stiffened laminated composite plates has been done to study the effect of stiffener configuration, number of layers and boundary conditions on the free vibration response of stiffened laminated composite plates. From the results reported herein, the following conclusions are obtained:

1. Presence, arrangement and configuration of stiffeners have important effects on the free vibration response of stiffened laminated composite plates which should be considered in the design of stiffened laminated composite plates.

2. As the number of stiffener increase the natural frequency increase with the increase of the number of modes for all number of layers.

3. The natural frequency is higher with model four where the four stiffeners are configuration in one direction than that with other models with the increase of the number of modes for all number of layers.
4. Boundary conditions of plates have a significant influence on the free vibration response of stiffened laminated composite plates where the natural frequency for clamped supported are higher than that for the simply supported with the increase of the number of modes for all models and all number of layers.

5. As the number of layers increases there is no much variation in the natural frequency for all models with the increase of the number of modes.

\section{REFERENCES}

[1] A.S. Ashour, 2009.The free vibration of symmetrically angle-ply laminated fully clamped skew plates. Journal of Sound and Vibration, 323, 444-450.

[2] A. K. Sharma and N. D. Mittal, 2013. Free vibration analysis of laminated composite plates with elastically restrained edges using FEM. Cent. Eur. J. Eng., 3(2), 306315 .

[3] B. S. Reddy, M. S. Reddy and V. Nageswara, 2013. Vibration analysis of laminated composite plates using design of experiments approach. International Journal of Scientific Engineering and Technology, Volume No.2, Issue No.1, pp. 40-49.

[4] G. Qing, J. Qiu and Y. Liu, 2006. Free vibration analysis of stiffened laminated plates. International Journal of Solids and Structures, 43, 1357-1371.

[5] H. K. Bhardwaj, J. Vimal and A. K. Sharma, 2015. Study of free vibration analysis of laminated composite plates with triangular cutouts. Engineering Solid Mechanics, 3, 43-50.

[6] L. Yanhong, L. Dinghe and W. Yanli, 2014. Free vibration analysis of stiffened composite laminated plates with interfacial imperfections. IAENG International Journal of Applied Mathematics, 44:1, IJAM.

[7] M. Ganapathi , A. Kalyani, B. Mondal and T. Prakash, 2009. Free vibration analysis of simply supported composite laminated panels. Composite Structures, 90, 100-103.

[8] M. S. Reddy, B. S. Reddy, V. N. Reddy and S. Sreenivasulu, 2012. Prediction of natural frequency of laminated composite plates using artificial neural networks. Engineering, 4, 329-337.

[9] R. Rikards, A. Chate and O. Ozolinsh, 2001. Analysis for buckling and vibrations of composite stiffened shells and plates. Composite Structures, 51, 361-370.

[10] T. I. Thinh and N. N. Khoa, 2008. Free vibration analysis of stiffened laminated plates using a new stiffened element. Technische Mechanik, Band 28, Heft 3-4, $227-$ 236.

[11] U. Topal and Uzman, 2008. Frequency optimization of laminated composite angle-ply plates with circular hole. Materials and Design 29, 1512-1517.

[12] U. Topal and Uzman, 2009. Frequency optimization of laminated skew plates. Materials and Design 30, 3180 3185 . 